\title{
Diversifikasi Olahan Nira Tebu Melalui Diseminasi Teknologi Mesin Pemeras Tebu di Desa Karangbener Kecamatan Bae Kabupaten Kudus
}

\author{
Sumarno, Carsoni, Ahmad Buchori \\ Universitas PGRI Semarang, Indonesia \\ sumarno@upgris.ac.id
}

Received: $21^{\text {st }}$ November 2019 | Accepted: $29^{\text {th }}$ July 2020 | Publihsed: $20^{\text {th }}$ August 2020

\section{Key word:}

technology dissemination; diversification of processed sugarcane juice; sugar cane presses machine

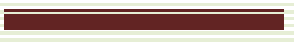

\section{Abstract}

Dissemination of technology products to the community aims to improve the welfare of sugar cane farmers in Karangbener Village, Bae District, Kudus Regency. The problem faced by farmers is the low price of sugar cane due to nonstandard yields and the low capacity of the sugar factory to receive sugar cane farmers in the harvest season. The strategy used is processing sugar cane by diversifying the processing of sugar cane through the dissemination of sugar cane presses. The strategy includes sugarcane cultivation socialization activities, diversification of sugar cane processing, training on the use of sugar cane presses, financial management training and training in selling and marketing sugarcane juice products to Sari Rejo and Bangun Harjo farmer groups with a total of 31 members. The results of the activity of making 3 units of sugarcane squeezer machines which have been handed over to farmer groups, the ability of farmer group members to diversify sugarcane juice preparations, the ability to operate and maintain sugarcane squeezer machines, and have an understanding of management and marketing of sugarcane processed diversified products.

\section{Kata Kunci}

diseminasi

teknologi, diversisifikasi olahan nira tebu, mesin pemeras tebu

\section{Abstract}

Diseminasi produk teknologi ke masyarakat ini bertujuan untuk meningkatkan kesejahteraan petani tebu Desa Karangbener, Kecamatan Bae, Kabupaten Kudus. Masalah yang dihadapi petani yaitu rendahnya harga jual tebu akibat rendemen yang tidak standar serta rendahnya kapasitas pabrik gula menerima tebu petani pada musim panen. Strategi yang digunakan yaitu mengolah tebu dengan mendiversifikasi olahan nira tebu melalui diseminasi mesin pemeras tebu. Strategi tersebut meliputi kegiatan sosialisai budidaya tebu, pelatihan diversifikasi olahan nira tebu, pelatihan penggunaan alat peras tebu, pelatihan manajemen finansial serta pelatihan penjualan dan pemasaran produk nira tebu kepada kelompok tani Sari rejo dan Bangun Harjo dengan total anggota 31 orang. Hasil kegiatan pembuatan 3 unit mesin pemeras tebu yang telah diserahkan kepada kelompok tani, kemampuan anggota kelompok tani mendiversifikasi olahan nira tebu, kemampuan mengoperasikan dan merawat mesin pemeras tebu, serta memiliki pemahaman pengelolaan dan pemasaran produk diversifikasi olahan tebu. 


\section{PENDAHULUAN}

Karangbener merupakan desa yang mempunyai potensi unggulan di bidang produksi tebu. Desa ini terletak di Kecamatan Bae yang berbatasan dengan Kecamatan Kudus disebelah selatan, Kecamatan Dawe di sebelah utara, Kecamatan Jekulo dan Mejobo di sebelah timur, serta Kecamatan Gebog di sebelah barat. Kecamatan Bae berada di kaki gunung Muria. Lahan pertanian Desa Karangbener sebagian besar dataran rendah dan berjenis tanah latorit dan gromosal, sehingga mendukung untuk budidaya tebu.

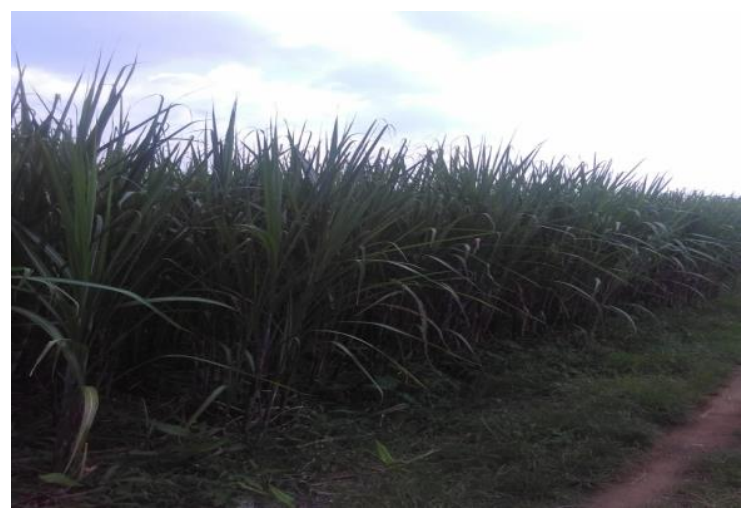

Gambar 1. Kondisi lahan tebu di Desa Karangbener.

Kondisi perekonomian masyarakat

Desa Karang Bener, khususnya petani maupun buruh tani perlu ditopang kegiatan ekonomi lain. Hal tersebut akibat semakin sempitnya lahan sawah dan secara umum lahan sawah ditanami dengan komoditas tebu. Tebu hasil perkebunan masyarakat Desa Karangbener selama ini hanya dijual ke Pabrik Gula Rendeng Kudus. Petani tebu sering mengalami kerugian yang diakibatkan untuk masuk ke penggilingan Pabrik Gula Rendeng masih banyak hambatan baik antrean giling, tingkat rendemen, maupun persaingan harga jual.

Hal tersebut menyebabkan beberapa petani membuat kelompok tani untuk meningkatkan daya saing. Selain itu, petani juga mengolah tebu untuk dijadikan gula tumbu. Hasil penelitian sebelumnya menyebutkan bahwa usaha gula tumbu merupakan salah satu usaha yang feasible dan layak untuk dilakukan (Permatasari \& Santosa, 2014)

Mayoritas petani yang membuat gula tumbu memiliki kapasitas produksi antara 26-39 kuintal gula tumbu per produksinya (6-10 hari) dengan jumlah pengrajin 26 jiwa dengan masing-masing antara produksi 26-32 kuintal sebanyak 13 jiwa dan 33-39 kuintal sebanyak 13 jiwa. Data ini menunjukkan rata-rata produksi petani per bulan sekitar 60-90 kuintal gula tumbu.

Kapasitas produksi tersebut dipengaruhi oleh waktu produksi dan jumlah kawah tempat memasak gula itu sendiri, semakin banyak jumlah kawah, maka semakin banyak pula jumlah produksinya. Namun demikian waktu produksi membutuhkan waktu lama, menghabiskan waktu 6-10 hari dalam satu 
kali produksi. Hal tersebut diakibatkan kemampuan alat yang digunakan menghasilkan nira tebu secara umum masih tradisional. Implikasi hal tersebut adalah produksi yang rendah, sedangkan masa tebang tebu singkat yaitu mulai bulan Mei-Desember.

Rata-rata gula tumbu dihargai Rp. 4.400,- sampai dengan Rp. 5.200,- per kilogram. Dengan demikian perlu upaya untuk meningkatkan kapasitas produksi petani tebu yang membuat gula tumbu melalui penggunaan mesin peras tebu yang memiliki kapasitas tinggi (Budiman \& Asari, 2015). Menindaklanjuti hal tersebut maka perlu diseminasi produk mesin peras tebu dalam pembuatan gula yang telah dibuat di Universitas PGRI Semarang sehingga mampu dimanfaatkan secara maksimal untuk membantu masyarakat membuat gula dan diversifikasinya.

\section{METODE}

Diseminasi teknologi melibatkan mitra kelompok tani Sari Rejo dan Bangun Harjo, Desa Karangbener Kecamatan Bae Kabupaten Kudus, serta LPPM UPGRIS sebagai lembaga penelitian dan pengembangan di Semarang yang mendampingi kegiatan. Pemilihan kelompok tani tersebut didasarkan pada permasalahan mitra yang membutuhkan teknologi mesin pemeras tebu dalam rangka mendiversifikasi produk olahan tebu.

Metode serta tahap-tahap Penerapan teknologi kepada masyarakat mellaui beberapa metode dan tahap, meliputi :

1. Identifikasi Kebutuhan masyarakat, dilakukan dengan observasi dan wawancara langsung dengan kelompok tani, meliputi produksi tebu, pemasaran produk tebu, maupun upaya alternatif mengolah tebu.

2. Perancangan, yaitu mendiskusikan rancangan program untuk mengolah tebu dan alternatif teknologi yang dapat didesimionasikan pada kelompok tani mitra pengabdian masyrakat.

3. Pembuatan, Tim pengadian bersama dengan anggota kelompok tani membuat mesin pemeras tebu. Keterlibatan anggota kelompok tani untuk memberikan masukan terhadap pembuatan mesin pemeras tebu.

4. Uji operasi dan pendampingan operasional. Uji operasi dan pendampingan operasional dilaksanakan dalam rangka menguji kesesuaian teknologi dengan kebutuhan kelompok tani mitra serta melatihkan operasi teknologi terhadap kelompok tani mitra.

5. Diseminasi teknologi tersebut kepada mitra untuk melatihkan operasi mesin pemeras tebu kepada anggota kelompok 
tani mitra, serta melatihkan diversifikasi produk olahan nira tebu, manajemen pemasaran maupun finansial.

\section{HASIL}

Hasil identifikasi kebutuhan mitra menunjukkan untuk meningkatkan produktivitas gula tumbu perlu adanya alat pemeras tebu yang meningkatkan bahan baku nira tebu. Hal tersebut diperlukan khususnya saat keterserapan hasil panen yang rendah serta rendahnya kualitas tebu.

Hasil diskusi pada tahap perancangan menunjukkan bahwa kelompok tani mitra menghendaki bagaimana kualitas produksi tebu meningkat serta alternatif teknologi untuk mengolah tebu serta alat pemeras tebu bertenaga mesin yang memiliki kapasitas tinggi. Berdasarkan hal tersebut maka dirancang mesin pemeras tebu serta teknologi untuk mengolah tebu. Rancangan ini disesuaikan dengan kebutuhan masyarakat dan mengacu pada prototype yang sudah ada (Jiwantoro dkk., 2013).

Selama proses pembuatan mesin pemeras tebu kelompok tani memberikan masukan tentang tinggi mesin menyesuaikan ukuran orang dewasa serta letak mesin diesel dalam rangka mesin pemeras tebuh, diharapkan menjadi lebih aman dan kuat terhadap getaran mesin. Pada tahap ini dihasilkan mesin pemeras tebu sesuai dengan masukan dari kelompok tani mitra.

Selanjutnya setelah dihasilkan mesin pemeras tebu maka dilakukan penyerahan mesin pemeras tebu serta melatihkan anggota kelompok tani mitra mengoperasikan mesin pemeras tebu. Hasil pada tahap menunjukkan anggota kelompok tani Sari Rejo dan Bangun Harjo mampu mengoperasikan mesin pemeras tebu.

Pelatihan tersebut juga dilengkapi dengan pelatihan diversifikasi olahan tebu, meliputi pelatihan pembuatan makanan dan minuman yang menggunakan bahan sari tebu hasil pemerasan. Hasil pelatihan menunjukkan anggota kelompok tani memiliki motivasi untuk mengolah tebu menjadi makanan dan minuan laternatif yang memiliki nilai ekonomi, apalagi setelah memperoleh manajemen pemasaran dan finansial.

\section{PEMBAHASAN}

Diseminasi teknologi tepat guna dilakukan beberapa tahap secara kesinambungan dan relevan dengan permasalah mitra (Buchori dkk., 2019). Lebih lanjut relevansi kegiatan-kegiatan dalam pada program diseminasi teknologi tepat guna dengan kehidupan dari 
kelompok tani mitra kegaiatan adalah

sebagaimana disajikan pada Tabel 1.

Tabel 1. Relevansi kegiatan dengan capaian hasil program diseminasi teknologi tepat guna mesin pemeras tebu untuk mendiversifikasi produk olahan nira tebu.

\begin{tabular}{|c|c|c|c|}
\hline No & Permasalahan & Kegiatan & Luaran \\
\hline 1 & $\begin{array}{l}\text { Produkstivitas anggota petani } \\
\text { tebu }\end{array}$ & $\begin{array}{l}\text { Memberikan penyuluhan dan } \\
\text { pendampingan berwirausaha } \\
\text { dibidang olahan nira tebu }\end{array}$ & $\begin{array}{l}\text { Munculnya semangat } \\
\text { berwirausaha khususnya di } \\
\text { bidang produk olahan nira tebu }\end{array}$ \\
\hline 2 & $\begin{array}{l}\text { Kebutuhan } \\
\text { mendiversifikasi produk } \\
\text { berbahan tebu berbasis } \\
\text { kelompok masyarakat untuk } \\
\text { peningkatan nilai ekonomi. }\end{array}$ & $\begin{array}{l}\text { Memberikan penyuluhan tentang } \\
\text { ragam produk olahan berbahan } \\
\text { tebu } \\
\text { Memberikan pelatihan pembuatan } \\
\text { beragam olahan makanan } \\
\text { berbahan nira tebu }\end{array}$ & $\begin{array}{l}\text { Tambahan pengetahuan tentang } \\
\text { pembuatan berbagai jenis } \\
\text { komoditas berbahan tebu. } \\
\text { Mampu membuat berbagai jenis } \\
\text { minuman dan makanan } \\
\text { berbahan olahan nira tebu }\end{array}$ \\
\hline 4 & $\begin{array}{l}\text { Pemerasan nira tebu } \\
\text { menggunakan alat tradisional }\end{array}$ & $\begin{array}{l}\text { Diseminasi mesin pemeras tebu } \\
\text { Memberikan pelatihan } \\
\text { penggunaan teknologi mesin } \\
\text { memeras tebu }\end{array}$ & $\begin{array}{l}\text { Mesin peras tebu } \\
\text { Keterampilan mengoperasikan } \\
\text { mesin pemerasan tebu }\end{array}$ \\
\hline 5 & $\begin{array}{l}\text { Pengelolaan pemasaran dan } \\
\text { keuangan dalam wirausaha }\end{array}$ & $\begin{array}{l}\text { Memberikan workshop } \\
\text { manajemen pemasaran online dan } \\
\text { pengelolaan keuangan }\end{array}$ & $\begin{array}{l}\text { pengetahuan dan dorongan } \\
\text { pengelolaan dan pemasaran } \\
\text { secara lebiih luas }\end{array}$ \\
\hline
\end{tabular}

Kegiatan diseminasi berhasil membuat mesin pemeras tebu sebanyak 3 unit dengan tenaga bensin yang diserahkan kepada kelompok tani Sari Rejo dan Bangun Harjo, Desa Karangbener, Kecamatan Bae, Kabupaten Kudus. Mesin tersebut merupakan bagian teknologi yang didesiminasikan kepada angggota kelompok tani, sebagai upaya untuk mengatasi permasalahan produksi atau hasil panen tebu yang seringkali tidak terserap pada pabrik gula.

Mesin pemeras tebu tersebut dimanfaatkan oleh kelompok tani untuk mengasilkan nira. Anggota kelompok tani mampu mengoperasikan mesin pemeras tebu dengan mudah. Hal tersebut rancangan mesin pemeras tebu disesuaikan dengan masukan dari anggota kelompok tani, sehingga mesin sesuai dengan kebutuhan kelompok tani. Hal ini juga mendorong kelompok tani untuk melakukan wirausaha untuk memperoleh alternatif pendapatan secara ekonomis dengan menggunakan mesin tersebut.

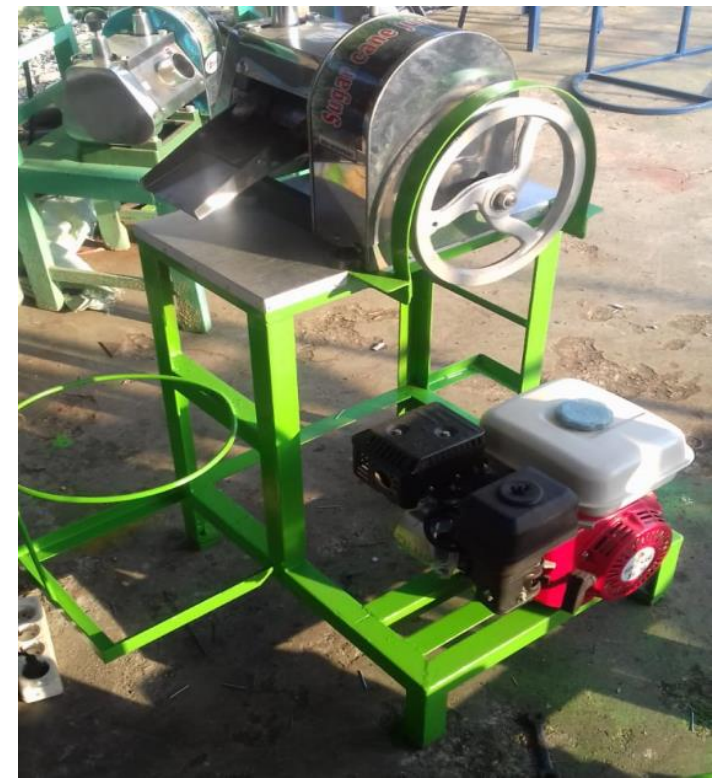

Gambar 2. Mesin Pemeras tebu siap diserahkan kepada kelonpok tani mitra kegiatan pengabdian. 


\begin{abstract}
Diseminasi teknologi yang dilakukan juga ditambahkan dengan pelatihan diversifikasi produk olahan tebu. Hal ini dilakukan agar petani memiliki alternative lain dalam mengolah nira tebu dan mendapatkan tambahan penghasilan dari hasil nilai tambah (added value) olahan tebu (Lestari dkk., 2016)
\end{abstract}

Pendapatan alternatif tersebut diperoleh dengan mengolah hasil pemerasan tebu, yang dijadikan sebagai bahan untuk membuat beragam minuman dan makanan seperti coro bikang, jamu, ager-ager. Berbagai alternatif varian makanan dan minuman menggunakan nira tebu sebagai bahan, dikemas sedemikian rupa sehingga memingkinkan untuk merambas pemasaran secara online

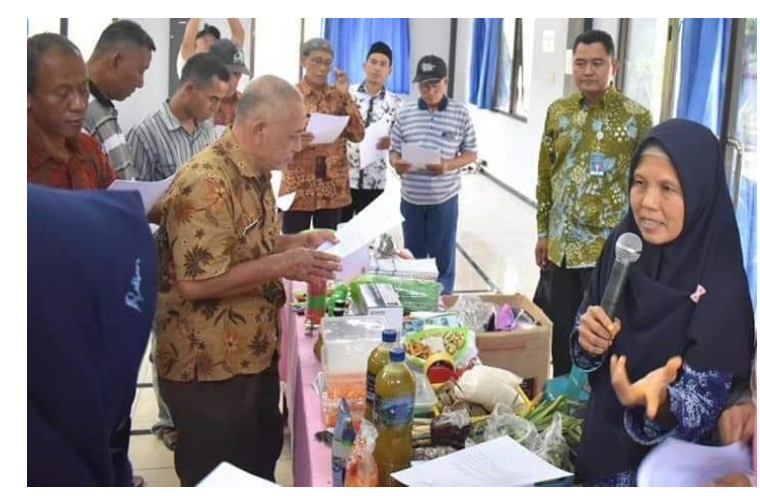

Gambar 3. Situasi pelatihan diversifikasi olahan nira tebu.

Salah satu pelatihan lain yang dilakukan adalah mendesain atau menentukan kemasan. Hal ini ditujukan agar tampilan hasil diversifikasi olahan gula tebu dapat menarik dan dapat dipasarkan dengan mudah serta layak untuk masuk ke pasar yang lebih besar dan modern khususnya untuk produk jamu, minuman, dan makanan (Wisdaningrum dkk., 2018)

Pemasaran online telah dilakukan dengan membuat akun di instagram dan membuat blog yang khusus dibuat untuk kelompok tani desa karangbener kecmatan bae kabupaten kudus disambut baik oleh anggota kelompok tani karena mendukung mereka untuk memperoleh akses yang lebih luas dalam pemasaran hasil olahan nira tebu (Hagijanto \& Maer, 2015)

\section{SIMPULAN}

Berdasarkan hasil kegiatan Diseminasi Teknologi Mesin Pemeras Tebu dalam Upaya Mendiversisikasi Olahan Nira Tebu di Desa Karangbener Kecamatan Bae Kabupaten Kudus, maka dapat disimpulkan sebagai berikut:

a) Anggota kelompok tani Sari Rejo dan Bangun Harjo menerima dengan baik diseminasi teknologi untuk mengatasi hasil panen tebu yang tidak terserap di pabrik gula.

b) Diseminasi mesin pemeras tebu mendorong anggota kelompok tani Sari Rejo dan Bangun Harjo berwirausaha melalui membuat makanan dan minuman berbahan nira hasil pemerasan tebu. 
c) Anggota kelompok tani Sari Rejo dan terdorong memanfaatkan teknologi untuk mengelola dan memasarkan hasil olahan tebu.

\section{SARAN}

Adapun saran berdasarkan hasil kegiatan Diseminasi Teknologi Mesin Pemeras Tebu dalam Upaya Mendiversisikasi Olahan Nira Tebu di Desa Karangbener Kecamatan Bae Kabupaten Kudus, maka adalah sebagai berikut:

a) Jumlah mesin pemeras tebu yang serahkan kepada kelompok tani, sehingga agar optimal dalam penggunaannya maka anggota kelompok tani harus membuat kesepakatan penggunaan mesin peeras tebu.

b) Anggota kelompok tani dapat berbagi varian olahan nira tebu, sehingga dapat membentuk semacam kelompok usaha bidang olahan produk berbahan tebu.

c) Anggota kelompok tani selanjtnya difasilitasi oleh pemerintah desa dan pihak terkait untuk menjaga kesinambungan diseminasi teknologi.

\section{UCAPAN TERIMA KASIH}

Ucapan terima kasih kami tujukan pada Kementerian Ristekdikti yang telah memfasilitasi terselenggaranya Diseminasi Teknologi Mesin Pemeras Tebu dalam
Upaya Mendiversifikasi Olahan Nira Tebu di Desa Karangbener Kecamatan Bae Kabupaten Kudus. Terima kasih juga disampaikan kepada LPPM UPGRIS yang telah memberikan dukungan dan penggunaan fasilitas dalam kegiatan pengabdian ini. Serta disampaikan kepada pemerintah Desa Karangbener atas fasilitasi koordinasi dengan kelompok tani selama pelaksanaan kegiatan.

\section{DAFTAR PUSTAKA}

Buchori, A., Widodo, S., Ristanto, S., \& Artiani, L. E. (2019). Diseminasi Teknologi Mesin Genset Tenaga Surya Bagi Masyarakat Terdampak Bencana Gunung Merapi Desa Wukirsari Kecamatan Cangkringan Kabupaten Sleman. Journal of Dedicators Community, 3(2), 8290.

Budiman, D. A., \& Asari, A. (2015). Evaluasi Kinerja Mesin Pemeras Tebu Untuk Produksi Gula Cair. Prosiding Seminar Nasional Pengembangan Teknologi Pertanian. https://doi.org/10.25181/prosemnas. v0i0.570

Hagijanto, A. D., \& Maer, B. D. A. (2015). Perancangan Media Promosi Gula Merah Tebu Cap Panela Di 
Surabaya. Jurnal DKV Adiwarna, 1(6), 12.

Jiwantoro, A., Argo, B. D., \& Nugroho, W.

A. (2013). Analisis Efektivitas

Mesin Penggiling Tebu dengan

Penerapan Total Productive

Maintenance (In Press, JKPTB Vol

1 No 2). Jurnal Keteknikan

Pertanian Tropis dan Biosistem, 1(2).

Lestari, S., Abidin, Z., \& Sadar, S. (2016).

Analisis Kinerja Rantai Pasok Dan

Nilai Tambah Produk Olahan

Kelompok Wanita Tani Melati Di

Desa Tribudisyukur Kecamatan

Kebun Tebu Lampung Barat.

Jurnal Ilmu Ilmu Agribisnis:

Journal of Agribusiness Science,

4(1), Article 1.

https://doi.org/10.23960/jiia.v4i1.\%

$\mathrm{p}$
Permatasari, D., \& Santosa, P. B. (2014). Analisis Pendapatan Usahatani Gula Tumbu (Kasus Kecamatan Dawe Kabupaten Kudus) [Other, Fakultas Ekonomika dan Bisnis]. http://eprints.undip.ac.id/45000/

Wisdaningrum, O., Rahayuningsih, R., \& Bariyyah, K. (2018). Pelatihan Proses Produksi dan Branding Packaging (Pengemasan) Pada Kelompok Penderes Gula Merah Desa Gintangan Kab. Banyuwangi. LOYALITAS, Jurnal Pengabdian Kepada Masyarakat, 1(2), 168179. 